\title{
Variation in diurnal and seasonal urban land surface temperature: landuse change impacts assessment over Lagos metropolitan city
}

\author{
Ayansina Ayanlade ${ }^{1}(D)$
}

Received: 26 August 2016/ Accepted: 7 October 2016/Published online: 7 November 2016

(C) Springer International Publishing Switzerland 2016

\begin{abstract}
Removal of vegetation to give space for urban expansion might result in the temperature rise in cities. The present study compares the LSTs derived from Moderate Resolution Imaging Spectroradiometer (MODIS) with observed air temperature from ground weather data. The natures of the materials that are usually found in the urban area are typically concrete and asphalt materials which affect the urban atmospheric system. In this study, variation in urban land surface temperatures (LST) using MODIS and in-situ meteorological data were examined. MODIS data and daily rainfall, minimum (Tm) and maximum (Tmx) temperature from ground weather station were used. The results reveal that average LSTs during the dry season are noticeably higher for both daytime during November: $34.62{ }^{\circ} \mathrm{C}$, December: $33.75{ }^{\circ} \mathrm{C}$, January: 34.68 ${ }^{\circ} \mathrm{C}$, February: $35.02{ }^{\circ} \mathrm{C}$ and March: $34.87^{\circ} \mathrm{C}$. There are notable differences in the LST observed between daytime and nighttime for both MOD11A2 and MYD11A2 and that of maximum and minimum air temperature from in-situ meteorological data. MOD11A2 is a better proxy for daily maximum and minimum air temperature than MYD11A2, though seasonal variations in the extent of LST occurs during the wet and dry season. The study shows that the contribution of the urban LSTs was comparatively smaller at night than the day, perhaps as result of the variations in the amount of solar radiation received by the day and night times.
\end{abstract}

Ayansina Ayanlade aayanlade@ oauife.edu.ng

1 Department of Geography, Obafemi Awolowo University, Ile-Ife, Nigeria
Keywords LST · Urban heat island - MODIS · Weather data

\section{Introduction}

The global growing trend of urbanization comes with consequences on the ecosystem such as depletion of land natural resources in many cities. The excessive upsurge of unguarded development in the urban centers induces the use of land for other purposes that would not complement the effect of human development on the urban environment. Studies have reported that the percentage of the green space and public open spaces that are supposed to have been preserved are being built-up in many cities areas in the world (Rosenzweig et al. 2006; Kim and Pauleit 2007; Qiao et al. 2013; Kandel et al. 2016). Loss of the green spaces may deprive and reduce biodiversity, and disrupt the structure and process of the urban ecosystem (Kim and Pauleit 2007) while conversely, the presence of green space mitigates by moderating the urban heat island effect (Yuan and Bauer 2007).

Recently, researchers have assessed the link between the urban land surface materials and urban thermal behavior ( $\mathrm{Lu}$ and Weng 2006; Weng and $\mathrm{Lu}$ 2008; Wang et al. 2016b). For example, Wang et al. (2016a) noted that removal of vegetation due to urban expansion might result in the minimum temperature rise by about $5^{\circ} \mathrm{K}$ in the newly developed of the Beijing-Tianjin-Hebei metropolitan area. Weng and $\mathrm{Lu}$ (2008) had earlier documented the relationship between change in urban land surface temperatures (LST) and the morphological changes in vegetation coverage and the impervious surface in the Indianapolis city of the United States America. The results from these studies show that urban areas may be more uncomfortable in the 
future due to urban expansion, an increase in the impervious surface, an increase in LST, and reduction of green space in cities areas.

Urban areas in Nigeria are currently overwhelmed by rapid population increase, poor infrastructure and an everincreasing number of urban slums across the country. The United Nation report has projected that cities in Nigeria are expected to grow by higher population of people over the next 40 years (UN 2012). This is an indicator that Nigeria will experience high probabilities of urban expansion, though; the major drivers of urban landuse change are basically the spatial interaction effects and policy variables (Bah et al. 2003; Braimoh and Onishi 2007). The natures of the materials that are usually found in the urban area are typically concrete and asphalt materials. They are used for most surface construction which mostly absorbs and stores heat energy much more effectively than the surrounding natural rural environment. It should be noted that the materials have different emission capacity. These factors, combined with the heat generated from vehicles, air conditioners, and industries enhances cities to generate, absorb and hold heat effectively. As a result, the heat captured during the day by diverse surfaces is gradually released at night (Lo and Quattrochi 2003; Solecki et al. 2005). Surprisingly, few studies have been conducted in Nigeria to assess variation in urban LST in some cities in the country.
What is obvious from these studies is the increasing urban temperature in some cities in Nigeria, compared to the surrounding rural areas (Balogun and Balogun 2014; Umar and Kumar 2014; Daniel 2015; Ayanlade 2016; Ibrahim Mahmoud et al. 2016). None of these studies compared satellite-derived temperature data with ground weather stations data. Thus, the present study examines the variation in urban LST using Moderate Resolution Imaging Spectroradiometer (MODIS) and in-situ meteorological data. The study aim at investigating variations in and compare the mean LST during dry and wet seasons from MODIS with ground meteorological data between 2002 and 2014 for selected sites and uses this to show the intensity of urban heat island (UHI) in a city in Nigeria.

\section{Materials and methods}

\section{Study area}

Lagos metropolis is located in the Gulf of Guinea, the south-western coast (see Fig. 1) and lies generally on lowlands part of Nigeria. The city is one of the highly populated and one of the fastest growing mega-cities in the West Africa, with nearly $70 \%$ of the population living in the slums areas (Adelekan 2010). The study site is located
Fig. 1 Map of the study area showing the landscapes and the location of selected sample sites

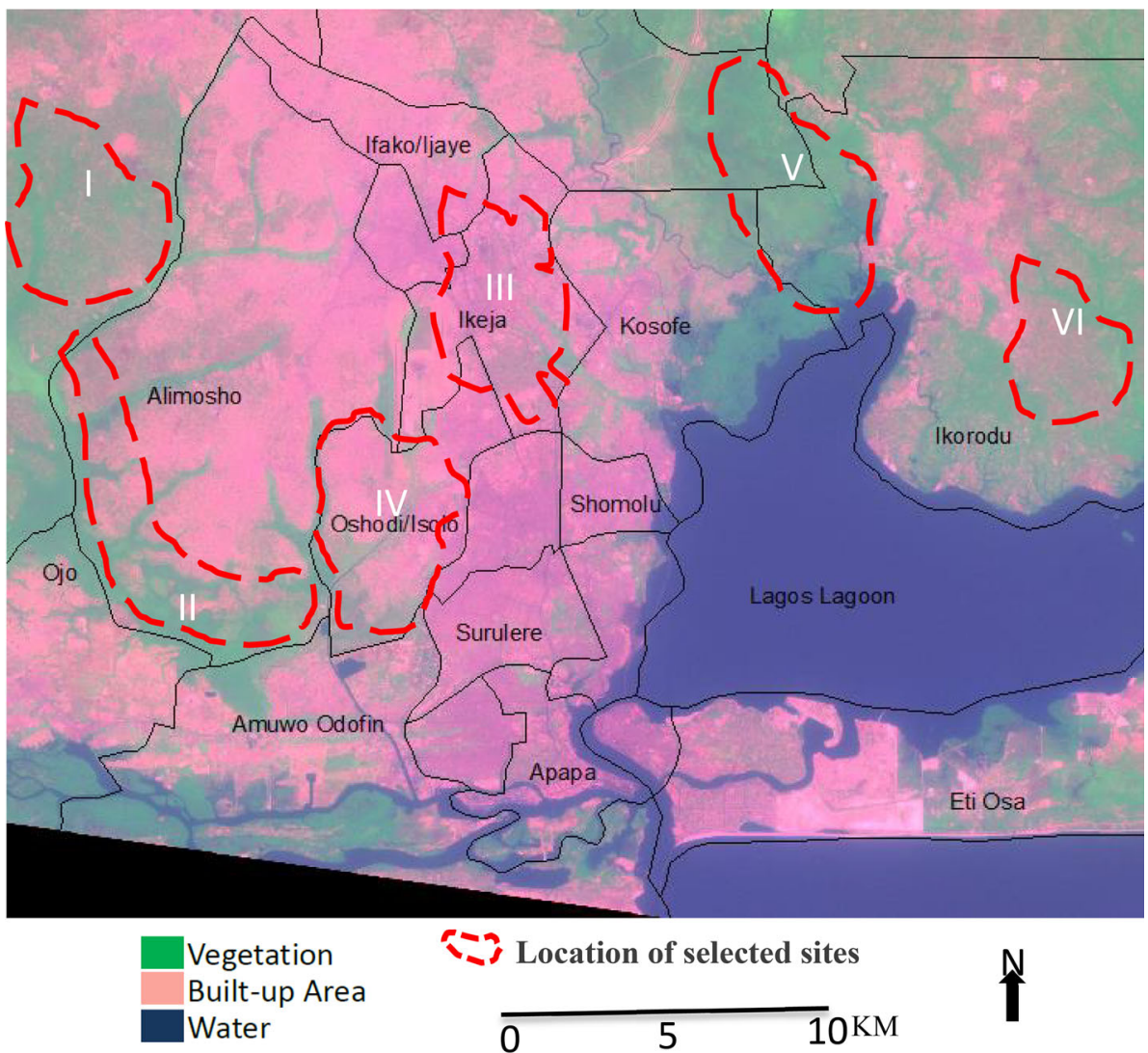


Table 1 Meteorological characteristics of the study area

\begin{tabular}{lcrll}
\hline Months & Number of rainy day & Rainfall & $T_{\mathrm{m}}$ & $T_{\mathrm{mx}}$ \\
\hline Jan & 1 & 24.04 & 23.03 & 33.19 \\
Feb & 2 & 40.83 & 22.68 & 32.15 \\
Mar & 6 & 72.30 & 21.48 & 31.90 \\
Apr & 9 & 148.48 & 22.59 & 30.25 \\
May & 12 & 198.37 & 20.70 & 30.11 \\
Jun & 16 & 288.01 & 20.82 & 29.36 \\
Jul & 13 & 217.67 & 20.79 & 28.06 \\
Aug & 11 & 91.54 & 21.16 & 28.06 \\
Sep & 12 & 197.81 & 21.29 & 29.88 \\
Oct & 10 & 162.38 & 21.60 & 30.21 \\
Nov & 4 & 94.53 & 20.57 & 31.48 \\
Dec & 2 & 26.75 & 20.92 & 31.05 \\
\hline
\end{tabular}

partly rainforest and swampy mangrove region of Nigeria. It has bi-modal rainfall peaks with nearly $2000 \mathrm{~mm}$ of mean annual rainfall (Oyewole et al. 2014). Table 1 shows the monthly rainfall, minimum (Tm) and maximum (Tmx) temperature from the ground weather station. The lowest Tm and Tmx occurs during the months from May to September, which is the peak period of the rainy season, but the high temperature usually records in the months of November to March (Oyewole et al. 2014; Ayanlade 2016). February is the hottest month in Lagos (Table 1). Over the past decades, deforestation resulting from rapid urban expansion, riverine flood, an increase in heat wave, coastal and flash flooding have been the major environmental problems in the city. This is because the rapid growth of the metropolis resulting from an increase in industrial activities and urbanization over the years has continued to exert enormous pressure on the environment's resources such as mangrove, swamp, and other coastal wetland vegetation. Studies have shown that removal of vegetation, one of the impacts of landuse/landcover change in the city, reduces the natural barrier to storms and other climate extreme events, thus resulting in changing in the LST (Breitmeier et al. 2009; Kleerekoper et al. 2012).

\section{Datasets and analysis}

Both satellite and in-situ climatological data were used in this study. A time series of Moderate Resolution Imaging Spectroradiometer (MODIS) data and meteorological stations data used in this study were collected during both rainy and dry seasons over the period of time from 2002 to 2014. MYD11A2 and MOD11A2 are 8-day data product of MODIS, which composed from the daily 1-km LST product (MYD11A1 and MOD11A products). MYD11A2 and MOD11A2 used in this study are day and nighttime LSTs and emissivity estimated from Bands 31 and 32. Sub-set of MODIS data were used to assess the mean LST during wet and seasons for selected sites. Daily rainfall, minimum and maximum temperature, between 2002 and 2014, were collected from Nigerian Meteorological Agency, Oshodi Lagos. In this study, the rainy season represents periods of reasonably high rainfall in the study area, from April to October, while dry season lasts from November to March. Rainfall and Temperature were used to understand the average temporal and seasonal rainfall and temperature patterns in the study area, and were compared with MYD11A2 and MOD11A2 dataset.

Observed air temperature from meteorological stations was compared with MODIS data over the period from the year 2002 and 2014. The LST values for the pixel in which the automatic meteorological station were used to create extracting MOD11A2 and MYD11A2 values and compared with maximum and minimum air temperature from meteorological station. The rainfall data were analyzed to assess the average monthly rainfall over the period. The analysis reveals two peaks rainfall periods: May to July and September to October, with rainfall being heaviest during the first peak period, but the dry season is the months from November to March. Selected sites were analysis to examine the variations LST over different landscapes. The selection was a purposive sampling method, covering the landscapes such as farmland area, sub-urban residential areas, commercial and downtown areas, urban residential area, and rural area which consist of vegetal cover. The temperature variations in these landscapes were assessed using LST parameters extracting from MOD11A2 and MYD11A2 metadata.

\section{Results and discussions}

\section{Variations in mean temperature from MODIS and observed air temperature}

The differences between the MODIS day and night temperature and observed air temperature are presented in Figs. 2, 3, 4 and 5. These figures compare the extent and rate of change in long-term temperature for MOD11A2, MYD11A2 and air temperature, maximum, and minimum, from the meteorological station, for both day and night over the period of study. The results show notable differences in the LST, observed between daytime and nighttime for both MOD11A2 and MYD11A2 values and that of maximum and minimum air temperature from in-situ data. Previous studies have reported the similar results in other part of the world. Typical examples of such studies are the works of Zhu et al (2013) and Wang et al (2016a). The major finding of this study, like other previous studies, is 

daily MOD11A1 products versus observed air temperature (Met)
Fig. 2 Time series of average

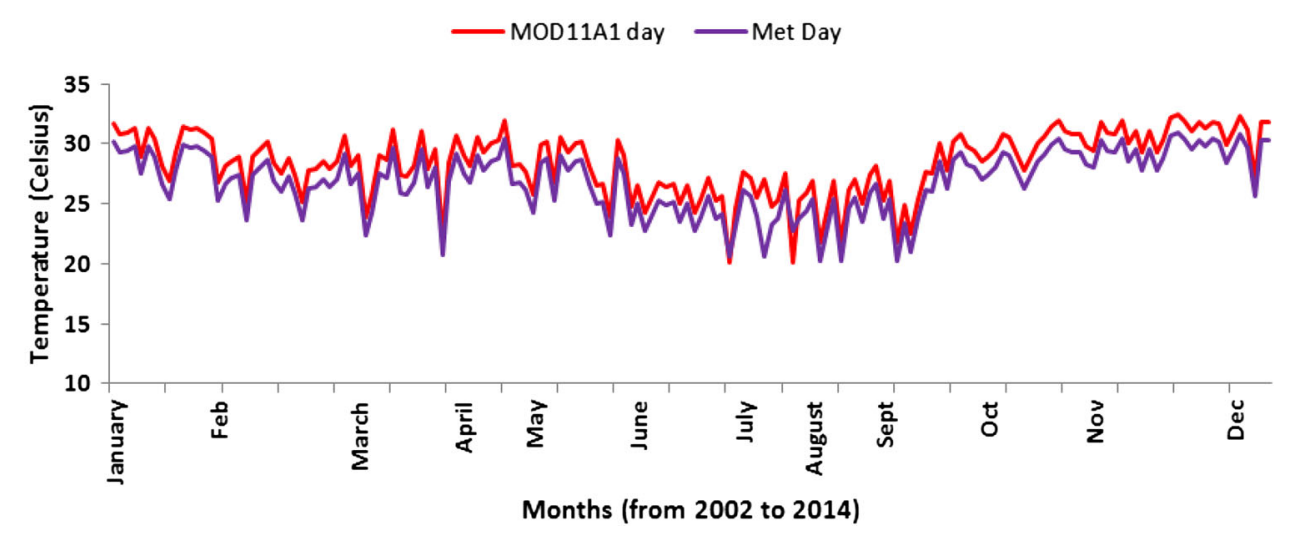

Fig. 3 Time series of average daily MOD11A1 products versus observed air temperature (Met)

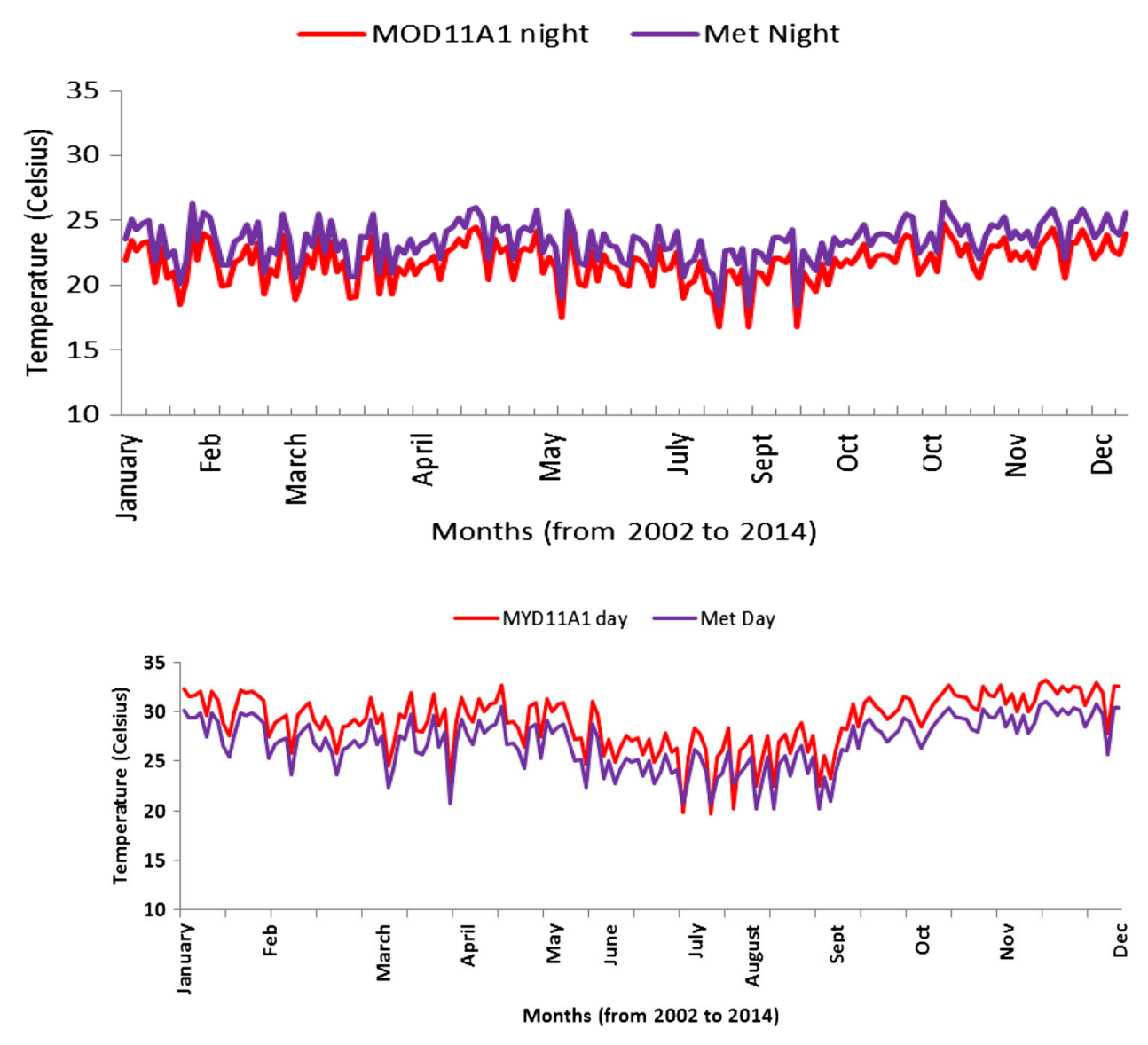

Fig. 4 Time series of average daily MYD11A1 products versus observed air temperature (Met) that MODIS products hold potential benefits of good estimation of spatial and temporal LST (Zhu et al. 2013; Wang et al. 2016a, b; Zhang et al. 2016). In the present study, however, cloud cover is a challenge with MODIS data, resulting to areas with no data, especially during the wet seasons. But, what is obvious from the present study is that MODIS product overestimated the LST during the daytime (Figs. 2, 4) and underestimate it during night time (Figs. 3, 5 ). It is observed that during the night, temporal agreements were observed (Fig. 5), much more in the dry season compared to the day time and wet season (Figs. 2, 4), In addition, the results also revealed that MOD11A2 is a better proxy for daily maximum and minimum air temperature than MYD11A2. This result is in confirmation of the study by Zhu et al (2013). The reason for this might be as a result of the differences in the time overpass time of both Terra and Aqua over the study area, thus results in variations in the estimation of air temperature between

In General, the results show higher in LSTs during the day time compared to night time. There appear to be seasonal variations in the extent of LST during the wet and dry MOD11A2 and MYD11A2. 
Fig. 5 Time series of average daily MYD11A1 products versus observed air temperature (Met)
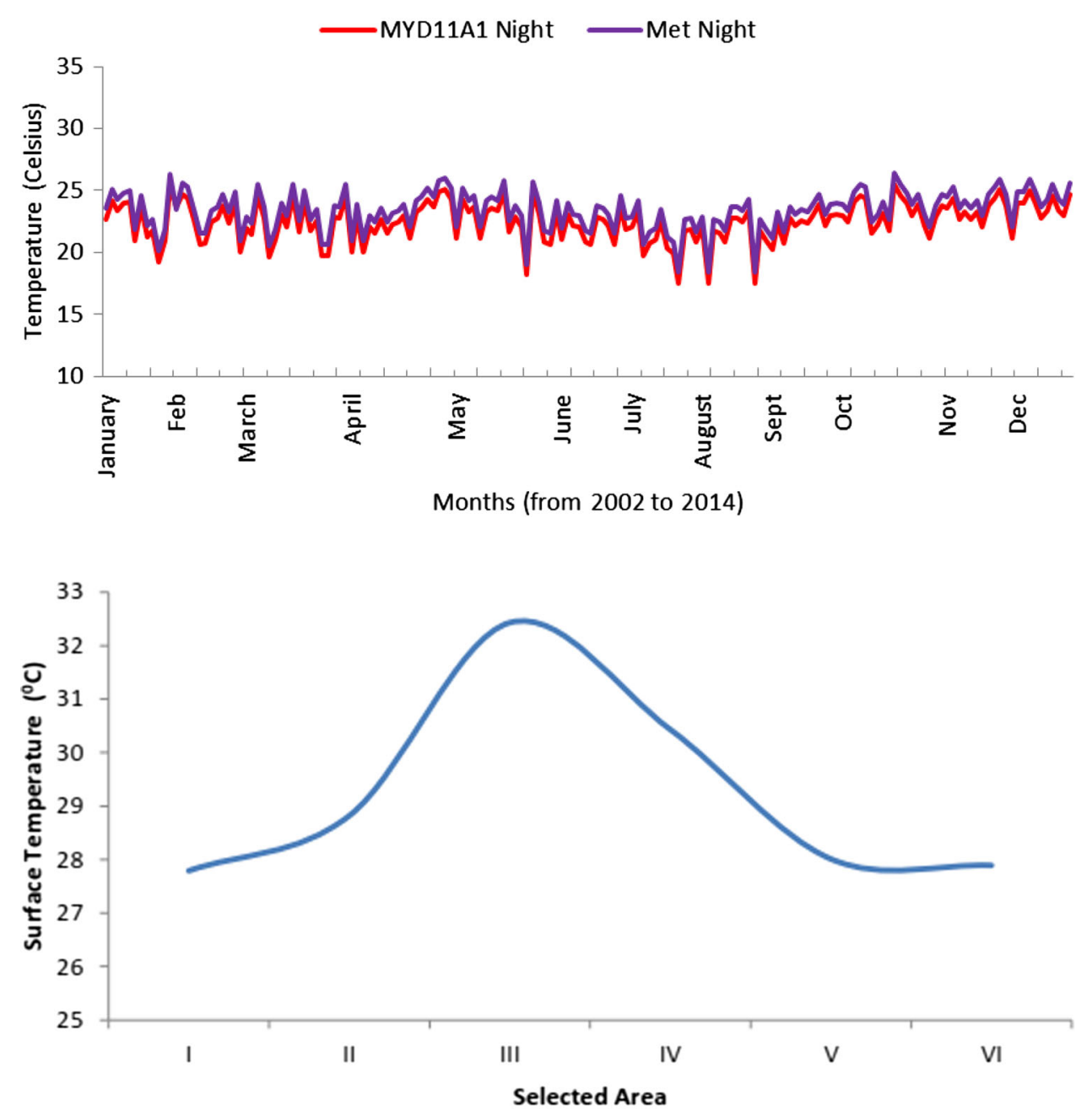

Selected Area
Fig. 6 Mean land surface temperature (SLST) during wet season from MODIS data between 2002 and 2014 for selected sites season, with the lowest in April to July and September to October, while the months from November to March appear higher. Average LSTs during dry season (Figs. 2, 3, 4 and 5) are noticeably higher for both daytime(November: $34.62{ }^{\circ} \mathrm{C}$, December: $33.75^{\circ} \mathrm{C}$, January $34.68^{\circ} \mathrm{C}$, February $35.02{ }^{\circ} \mathrm{C}$ and March : $34.87^{\circ} \mathrm{C}$ ) and nighttime (November: $27.46{ }^{\circ} \mathrm{C}$, December: $24.42{ }^{\circ} \mathrm{C}$, January: $25.57{ }^{\circ} \mathrm{C}$, February: $25.86{ }^{\circ} \mathrm{C}$ and March: $27.76^{\circ} \mathrm{C}$ ) compare to wet seasons. The least wet season average LST occurs during the months of July and August (with less than $20^{\circ} \mathrm{C}$ ). Two major factors are responsible for these variations; the seasonal variations in the amount of rainfall and the monthly variations in solar radiation and percentage of cloud cover over the study area. Wet season receives much more rainfall compares to dry season, with the peak rainfall months to be from May to July and September to October, while the least rainfall occurs during the months from November to March. This might result from interactions and variations in the Intertropical Convergence Zone (ITCZ) associated with the coming onshore of a warm, humid maritime tropical air mass and hot and dry continental air mass. Also, the monthly variations in solar radiation and percentage of cloud cover over the study area results in seasonal and diurnal variations in LSTs. Effects of the solar radiation and cloud cover might be as a result of the closeness of the study area to the equator and the Gulf of Guinea.

\section{Mean seasonal land surface temperature for selected sites}

The study further assessed the mean Seasonal Land Surface Temperature (SLST) from MODIS data between 2002 and 2014 for selected sites. The selected sites vary in terms of the landuse and land cover (Table 2), consisting of commercial and downtown (Site III), urban residential area (Site IV), suburban residential areas (Sites II and V), rural area (Site VI) and farmland area (Site I). Generally, the LST values were higher during the dry seasons compared to wet seasons in all study sites (Figs. 6, 7). In all seasons, the LST was on highest in study site III follow by IV, while the lowest occurred in sites I and VI (Table 2) with LST of 
Fig. 7 Mean land surface temperature (LST) during dry season from MODIS data between 2002 and 2014 for selected sites

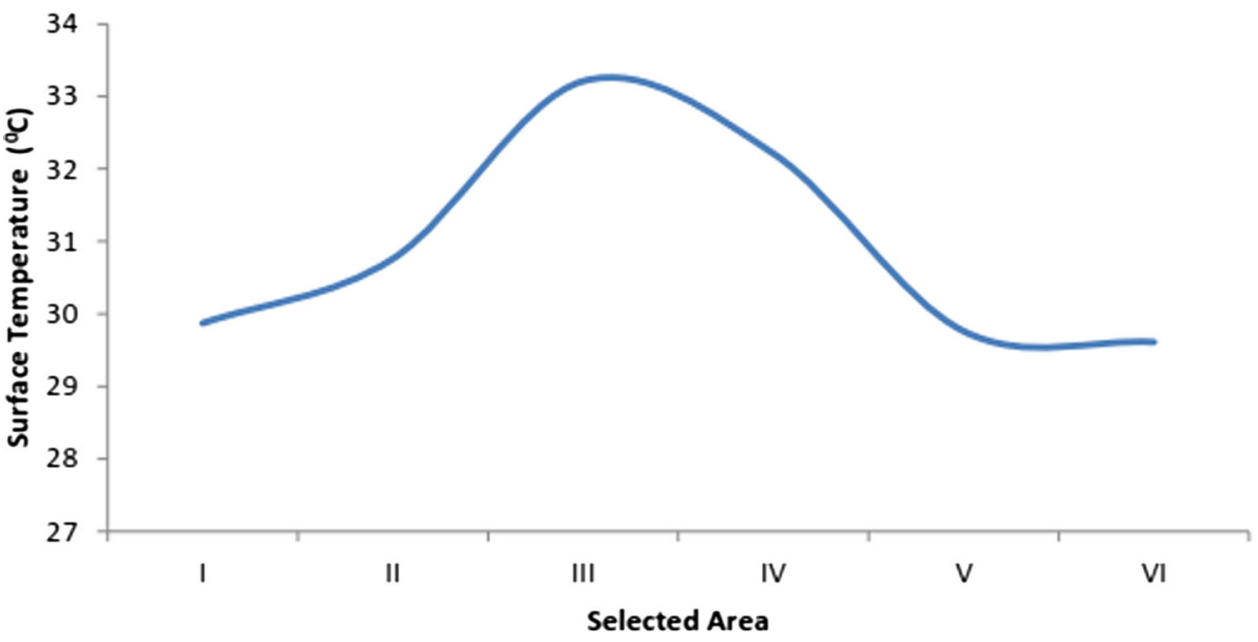

Table 2 Mean seasonal land surface temperature (SLST) from MODIS data between 2002 and 2014 for selected sites

\begin{tabular}{|c|c|c|c|}
\hline $\begin{array}{l}\text { Selected } \\
\text { sites }\end{array}$ & Description & $\begin{array}{l}\text { Mean SLST } \\
\text { wet season }\end{array}$ & $\begin{array}{l}\text { Mean SLST dry } \\
\text { season }\end{array}$ \\
\hline I & $\begin{array}{l}\text { This area is mainly farmland area, located around Ota community in Ogun state, Northwest of } \\
\text { Lagos. }\end{array}$ & 27.7 & 29.8 \\
\hline II & $\begin{array}{l}\text { The zone is sub-urban residential areas, mainly along Alimosho community of Lagos, which } \\
\text { consisting of urban fringe. }\end{array}$ & 28.8 & 30.7 \\
\hline III & $\begin{array}{l}\text { This site is mainly commercial and downtown areas, consisting of Ikeja and Ilupeju of Lagos, } \\
\text { which is the core urban part of the study area. }\end{array}$ & 32.4 & 33.2 \\
\hline IV & This area consists of urban residential area, mainly the around Oshodi and Ijegun areas. & 30.4 & 32.2 \\
\hline $\mathrm{V}$ & $\begin{array}{l}\text { This site is located around sub-urban residential area with some green cover, mainly around } \\
\text { Isawo area. }\end{array}$ & 28.0 & 29.7 \\
\hline VI & This is mainly rural area consists of vegetal cover and some houses, along Isiu community & 27.8 & 29.6 \\
\hline
\end{tabular}

about 270 and $290{ }^{\circ} \mathrm{C}$ during dry and wet seasons respectively (Figs. 6, 7). The reasons for variations in LSTs values for these sites over the study period are very clear. Firstly, sites III and IV are the core center of commercial activities and the principal residential zone of Lagos, while sites I and VI are rural areas consist of vegetal cover and some few houses.

The replacement of vegetal surfaces by built-up surfaces changes the LST characteristics in the urban area. For example, sites III and IV are known for low vegetal cover, high intensity of pavements and concrete buildings, which has higher percentage of non-reflective and waterresistant materials. Studies have reported that trees and vegetation provide shade, which helps lower surface temperatures in urban areas. They also release water to the air (through evapotranspiration processes), which helps in the cooling system. Urban areas have more dry, paving and rooftops, which evaporate less water, due to the removal of vegetation to give way to urban expansion (Coutts et al. 2007; Amiri et al. 2009; JACOB 2015). The results from the present study show that variations in the landscapes between urban and rural areas exhibit variations in their LSTs. Tree planting during development and redevelopment is critical to achieving a reduction in Urban LSTs in Lagos, because trees have a cooling effect and the moisture transpired through leaf surfaces (Solecki et al. 2005). Previous studies have shown that urban development reduces vegetative cover, thus adds heat absorbing surfaces such as rooftops, buildings, and paving. Besides, increased air pollution and greenhouse gas emissions from industrial areas and automobiles system, make the LST in sites III and IV higher than that of I and VI in all seasons in Lagos metropolis. It has been reported in the literature that high levels of pollution in industrial areas of cities increases the LST, because greenhouse gas emissions change the atmospheric properties, thus raises the temperature of the urban areas. Heat is also added from other sources in cities such as fuel combustion and air conditioning units (Solecki et al. 2005; Rosenzweig et al. 2006). Consequently, areas in and around cities are generally warmer than comparable rural areas (Oke 1982). 


\section{Conclusions}

This study aimed at examining the extent and rate of change in long-term temperature for MOD11A2, MYD11A2, and air temperature, maximum, and minimum, from the meteorological station, for both day and night in an urban area. This was achieved by assessing both seasonal and the daytime/nighttime differences in LSTs in different landuse categories. In general, major finding of this study can be summarized that: the MODIS data, MOD11A2 is a better proxy for daily maximum and minimum air temperature than MYD11A2, and seasonal variations in the extent of LST occurs during the wet and dry season, with the lowest in April to July and September to October, while the months from November to March appear higher.

Similarly, the arrangement of buildings affect wind flow, solar energy distribution and energy balance in urban, hence change the LST (Ishugah et al. 2014). In Lagos, the narrow arrangements of buildings in residential areas constitute urban canyons, which constrain the emission of the radiation from core urban areas. The construction materials commonly used in urban areas such as concrete and asphalt have significant impacts on LST within the urban areas compared to rural areas. Studies have also reported that the tall buildings within urban industrial areas create urban canyon effect which encourages multiple surfaces reflection of radiation, therefore, change urban LST (Guhathakurta 2013; Skelhorn et al. 2016).

The majority of these studies noted the variations in the contributions of landscapes to seasonal and diurnal and LST, but they concluded that urban land was the most important contributor to increases in local LSTs. The reason for this is obvious from the findings of the present study; the urban centre of Lagos is clustered into highdensity population and industrial areas with dense buildings and little vegetation. One of the major findings of this study is that contribution of urban land to the urban LSTs was comparatively smaller at night than the day. This might be due to the variations in the amount of solar radiation received by the day and night times. Also, variation in seasonal and diurnal LSTs might be as a result of the monthly variation in solar radiation and percentage of cloud cover over the study area. The high intensity of UHI in the study might also be associated with the reduction in the surface heat release efficiency due to reflection and absorption by the urban canopy. In an urban centre, there appears to be a less energy loss due to latent heat evaporation from the impervious urban surfaces and these resulted in high rate of heat storage in urban surfaces compares to rural areas, which has impacts on human health (Tan et al. 2010; Shahmohamadi et al. 2011;
Jenerette et al. 2016; Lowe 2016). Tan et al. (2010) and Lowe (2016) had earlier reported the implications of UHI intensity on human well-being. The result of these studies showed that warmer conditions in cities will affect human comfort and increase demand for air conditioning, resulting to increase in energy demand during the extreme warm condition, which might lead to greater risks in the future local climate.

Acknowledgments The author acknowledges the United States Geological Survey for providing the free access to the Moderate Resolution Imaging Spectroradiometer (MODIS) data used in this study. Thanks to the reviewers for critical reviews of the manuscript.

\section{References}

Adelekan IO (2010) Vulnerability of poor urban coastal communities to flooding in Lagos, Nigeria. Environ Urban 22:433-450

Amiri R, Weng Q, Alimohammadi A, Alavipanah SK (2009) Spatialtemporal dynamics of land surface temperature in relation to fractional vegetation cover and land use/cover in the Tabriz urban area, Iran. Remote sens Environ 113:2606-2617

Ayanlade A (2016) Seasonality in the daytime and night-time intensity of land surface temperature in a tropical city area. Sci Total Environ 557:415-424

Bah M, Cissé S, Diyamett B, Diallo G, Lerise F, Okali D, Okpara E, Olawoye J, Tacoli C (2003) Changing rural-urban linkages in Mali, Nigeria and Tanzania. Environ Urban 15:13-24

Balogun IA, Balogun AA (2014) Urban heat island and bioclimatological conditions in a hot-humid tropical city: the example of Akure, Nigeria. DIE ERDE-J Geogr Soc Berlin 145:3-15

Braimoh AK, Onishi T (2007) Spatial determinants of urban land use change in Lagos, Nigeria. Land Use Policy 24:502-515

Breitmeier H, Kuhn J, Schwindenhammer S (2009) Analyzing urban adaptation strategies to climate change: a comparison of the coastal cities of Dhaka, Lagos and Hamburg. In. Proc Contribution to the Panel, Regieren im Klimawandel Section, Regierungssystem und Regieren in der Bundesrepublik Deutschland, DVPW-Kongress

Coutts AM, Beringer J, Tapper NJ (2007) Impact of increasing urban density on local climate: spatial and temporal variations in the surface energy balance in Melbourne, Australia. J Appl Meteorol Climatol 46:477-493

Daniel OA (2015) Urban extreme weather: a challenge for a healthy Living environment in Akure, Ondo State, Nigeria. Climate 3:775-791

Guhathakurta S (2013) A Review of "Heat Islands: understanding and Mitigating Heat in Urban Areas" Lisa Gartland. (2011). London, UK: Routledge. 208 pages. \$64.95 (paperback). J Am Plan Assoc 79:256-257

Ibrahim Mahmoud M, Duker A, Conrad C, Thiel M, Shaba Ahmad H (2016) Analysis of settlement expansion and urban growth modelling using geoinformation for assessing potential impacts of urbanization on climate in Abuja City, Nigeria. Remote Sens $8: 220$

Ishugah T, Li Y, Wang R, Kiplagat J (2014) Advances in wind energy resource exploitation in urban environment: a review. Renew Sustain Energy Rev 37:613-626

Jacob RJ (2015) Effects of urban growth on temporal variation of surface temperature in katsina metropolis, nigeria. Department of geography, Faculty of science, Ahmadu Bello University, Zaria 
Jenerette GD, Harlan SL, Buyantuev A, Stefanov WL, Declet-Barreto J, Ruddell BL, Myint SW, Kaplan S, Li X (2016) Micro-scale urban surface temperatures are related to land-cover features and residential heat related health impacts in Phoenix, AZ USA. Landscape Ecol 31:745-760

Kandel H, Melesse A, Whitman D (2016) An analysis on the urban heat island effect using radiosonde profiles and Landsat imagery with ground meteorological data in South Florida. Int J Remote Sens 37:2313-2337

Kim K-H, Pauleit S (2007) Landscape character, biodiversity and land use planning: the case of Kwangju City Region, South Korea. Land Use Policy 24:264-274

Kleerekoper L, van Esch M, Salcedo TB (2012) How to make a city climate-proof, addressing the urban heat island effect. Resour Conserv Recycl 64:30-38

Lo C, Quattrochi DA (2003) Land-use and land-cover change, urban heat island phenomenon, and health implications. Photogramm Eng Remote Sens 69:1053-1063

Lowe SA (2016) An energy and mortality impact assessment of the urban heat island in the US. Environ Impact Assess Rev 56:139-144

Lu D, Weng Q (2006) Spectral mixture analysis of ASTER images for examining the relationship between urban thermal features and biophysical descriptors in Indianapolis, Indiana, USA. Remote Sens Environ 104:157-167

Oke TR (1982) The energetic basis of the urban heat island. Q J R Meteorol Soc 108:1-24

Oyewole J, Thompson A, Akinpelu J, Jegede O (2014) Variation of rainfall and humidity in Nigeria. Methodology 4

Qiao Z, Tian G, Xiao L (2013) Diurnal and seasonal impacts of urbanization on the urban thermal environment: a case study of Beijing using MODIS data. ISPRS J Photogramm Remote Sens 85:93-101

Rosenzweig C, Solecki W, Slosberg R (2006) Mitigating New York City's heat island with urban forestry, living roofs, and light surfaces. A report to the New York State Energy Research and Development Authority

Shahmohamadi P, Che-Ani A, Etessam I, Maulud KNA, Tawil NM (2011) Healthy environment: the need to mitigate urban heat island effects on human health. Proc Eng 20:61-70
Skelhorn CP, Levermore G, Lindley SJ (2016) Impacts on cooling energy consumption due to the UHI and vegetation changes in Manchester, UK. Energy Build 122:150-159

Solecki WD, Rosenzweig C, Parshall L, Pope G, Clark M, Cox J, Wiencke M (2005) Mitigation of the heat island effect in urban New Jersey. Glob Environ Change Part B Environ Hazards 6:39-49

Tan J, Zheng Y, Tang X, Guo C, Li L, Song G, Zhen X, Yuan D, Kalkstein AJ, Li F (2010) The urban heat island and its impact on heat waves and human health in Shanghai. Int J Biometeorol $54: 75-84$

Umar UM, Kumar JS (2014) Spatial and Temporal Changes of Urban Heat Island in Kano Metropolis, Nigeria. Int J Res Eng Sci Technol 1

UN U (2012) World Urbanization Prospects: The 2011 revision: United Nations. Department of Economic and Social Affairs. Population Division

Wang J, Huang B, Fu D, Atkinson PM, Zhang X (2016a) Response of urban heat island to future urban expansion over the BeijingTianjin-Hebei metropolitan area. Appl Geogr 70:26-36

Wang Y, Tang X, Yu L, Hou X, Munger JW (2016b) Comparison of net ecosystem carbon exchange estimation in a mixed temperate forest using field eddy covariance and MODIS data. SpringerPlus 5:1

Weng Q, Lu D (2008) A sub-pixel analysis of urbanization effect on land surface temperature and its interplay with impervious surface and vegetation coverage in Indianapolis, United States. Int J Appl Earth Obs Geoinf 10:68-83

Yuan F, Bauer ME (2007) Comparison of impervious surface area and normalized difference vegetation index as indicators of surface urban heat island effects in Landsat imagery. Remote Sens Environ 106:375-386

Zhang H, Zhang F, Ye M, Che T, Zhang G (2016) Estimating daily air temperatures over the Tibetan Plateau by dynamically integrating MODIS LST data. Journal of Geophysical Research: Atmospheres

Zhu W, Lü A, Jia S (2013) Estimation of daily maximum and minimum air temperature using MODIS land surface temperature products. Remote Sens Environ 130:62-73 